\title{
XXVI. Reply to the statement respecting the discovery of Cygnus Bewickii, published in the Phil. Mag. and Annals for August
}

\section{W. Yarrell Esq. F.L.S.}

To cite this article: W. Yarrell Esq. F.L.S. (1830) XXVI. Reply to the statement respecting the discovery of Cygnus Bewickii, published in the Phil. Mag. and Annals for August, Philosophical Magazine Series 2, 8:45, 167-169, DOI: 10.1080/14786443008675399

To link to this article: http://dx.doi.org/10.1080/14786443008675399

曲 Published online: 13 Jul 2009.

Submit your article to this journal $[\pi$

Џll Article views: 2

Q View related articles $\sqsubset$ 
oxide (Ann, Phil. iii. \$58) : and the mean taken is inclined conformably.

The insertion of any experiments of my own has been avoided, as needlessly swelling this paper, which proceeds on other grounds, and is already too long. For the same reason, the corresponding tables of oxides and acids are withheld; but if you find this deserving of publication, they can be forwarded at a future time.

Plymonth, April 10, 1830. I am yours, \&c. John Prineaux.

XXVI. Reply to the Statement respecting the Discovery of Cygnus Bewickii, published in the Phil. Mag. and Annals for August. By W. YarRelL, Esq. F.L.S.

To the Editors of the Philosophical Magazine and Annals. Gentlemen,

A LTHOUGH anonymous accusations can have little influence with your readers, and might therefore safely be treated with the neglect they merit; I yet, in self-defence, request insertion in your Magazine, of the following brief observations, in answer to a letter, addressed to you by a member of the Natural History Society of Newcastle-upon-Tyne, which appeared in your 44 th Number, published at the com? mencement of the present month.

It is first recessary that I should justify the opinion I gave by letter, that the distinctions described as existing in the parts of two swans might be occasioned by "age, sex, or accidental circumstances." For this purpose I shall quote, verbatim, the description itself, as sent me in March 1829, at which time the opinion was given.

"A young man, of the name of -__, who has given considerable attention to the ornithological part of Natural History, has the breast-bone and trachea of the common wild swan and of the new one; and our joint observations are as follows :

"The new species has eight ribs, and the old one only seven; the two specimens of the breast-bone are the same length, ten inches from the extremity of the merry-thought (where it joins to the elbow of the neck-bone) to the other end of the breastbone; but whereas in the common wild swan the bend of the trachea takes place seven inches from the extremity of the merry-thought; in the new one it is only four inches and a half. In the common wild swan the wind-pipe on entering the breast-bone is nearly round; in the new kind, so much flattened as to equal half an inch by a quarter. In the com- 


\section{$168 \mathrm{Mr}$. Yarrell's Reply on the Discovery of Cygnus Bewickii.}

mon wild swan the junction of the wind-pipe with the bronchial pipes takes place just underneath the bend of the merrythought; but in the new one, exactly under the hind bend of the wind-pipe; and finally, in the new kind the bronchial tubes are much shorter. I am afraid I have only given a very bungling description, but I hope, such as it is, it may be acceptable. I quite regret I cannot draw sufficiently well to send you a sketch of the two."

Such is the description; and having stated it, I leave it to the opinion of any person conversant with the subject, whether I should have been warranted in deciding that the differences were such as would constitute a new species. How few are there even now, with the figures of both species before them, who would be able to recognise either from such a description! And was I not justified in supposing there might have been "error of observation"? To say nothing of the confusion which renders much of this description unintelligible, it is quite clear from what we now know, that in more than one part of it, for 'old species' we must read 'new species', and vice versâ.

The new light stated by your anonymous correspondent to have afterwards dawned upon me, he ought also in justice to have added, was in the month of November 1829, and was the legitimate consequence of the acquisition of new materials. And surely I cannot with fairness be accused of any endeavour to depreciate the merits of $\mathrm{Mr}$. Wingate, whom I have never spoken to or even seen, when in December last I offered to him, thus wholly unknown to me except by name, the materials I possessed, to complete his paper; nor that I exhibited any intention of keeping him out of sight, when, after he had declined publishing, I included in my statement a notice of his discovery of the same bird, with a date ten months antecedent to my own paper.

$I$ have reason to believe, from several circumstances, that there was a scarcity of materials at Newcastle, and that they were insufficient for framing a description of this bird, as regarded the internal construction.

At the end of December I received a letter from Mr. Selby, requesting to be allowed to make use of some observations in a letter of mine on the subject of this bird, with any further remarks, and the use of any drawings I possessed relating to this species, which, to use that gentleman's own words, he writes, "you so appropriately suggest should be named after our celebrated countryman the late Mr. Bewick." The materials offered Mr. Wingate I transferred to Mr. Selby, with all the additions, which, during the interval, had come to my knowledge, 
knowledge, at the same time stating, that, as Mr. Wingate had declined publishing, and I had in the mean time obtained five additional examples of the new species, I had drawn up a peper from my own materials, which $I$ had sent in to the Linnæan Society, with all the drawings $I$ possessed on the subject. Mr. Selby's paper, I have no doubt, will be worthy his high and deserved reputation; and the more information we obtain of so interesting an addition to our native Fauna, the better.

I regret sincerely the necessity of referring to private correspondence; but the contents of letters have been quoted against me, and self-justification must be my apology.

I am, Gentlemen, yours, \&c.

Ryder Street, St. James's, Aug. 10, 1830.

WM. YARRELL.

XXVII. An Attempt to explain theoretically the different Refrangibility of the Rays of Light, according to the Hypothesis of Undulations. By the Rev. J. ChaL.LIs, Fellow of Trinity College Cambridge, and of the Cam. Phil. Soc.*

THE object of this communication is to follow up an idea advanced by Dr. Young, to explain theoretically the different refrangibility of the rays of light. (Lectures on Natural Philosophy, vol, ii. p. 623.) His notions on this subject have not met with the attention they deserve, probably because they are vague, and are not supported by mathematical calculation. There is much plausibility in his leading idea, viz. that the velocity of propagation of the æthereal undulations which traverse any medium, is modified by the vibrations of the material atoms of the medium, and differently according to the different frequency of the undulations: but the precise manner of the modification is probably not such as he supposes, and is open to further consideration.

For the object proposed, it will be necessary to attend to the manner in which a series of undulations is reflected when they encounter an obstacle. Suppose the fluid to be such that the pressure is proportional to the density, $p=a^{2}(1+s)$; and the portion of it we consider, to be included in a slender cylindrical tube. Let two series of undulations, equal in every respect, and generated under circumstances exactly alike, be propagated in opposite directions along the tube. By the principle of the coexistence of small vibrations, these undulations will be propagated in their respective directions with-

* Communicated by the Author.

N.S. Vol. 8. No. 45. Sept. 1830.

Z

out 